\title{
The Social Construction of Foreigners and Its Transformation in rural areas in South Korea
}

\author{
Yoon Seok Jung (Research Professor) \\ Institute of Governmental Studies, Korea University \\ Jungjanglo@gmail.com
}

\begin{abstract}
South Korea is no longer a homogeneous country. Since the mid-1990s, South Korea has demographically changed due to increasing the number of foreigners. During two decades, foreigners have been socially constructed by Korean ordinary people who have images about foreigners. The result of this study shows that although the difference between rural and urban area was not big, adults in rural were more favorable to foreign immigrants and emphasized civil elements rather than ethnic elements as conditions to be truly Korean. However, among teenagers, the rural youth were tended to be relatively conservative. They were less favorable to foreign immigrants and emphasized ethnic elements as compared to the urban youth. This tendency was opposite to the result of adult's case.
\end{abstract}

Keywords: Foreign immigrants; Social construction; Attitude to multiculturalism; Urban and rural areas.

\section{Introduction}

Although some Korean scholars have questioned the idea that Korea is a single-race country, ordinary South Korean people has long considered that Korea is an ethnically homogeneous society. However, since the mid-1990s, South Korea has demographically changed due to increasing the number of foreigners. They have immigrated from their countries to South Korea for better life. Recently, the population of foreigners living in South Korea is estimated at over two million.

During two decades, associating with many events and situations, they have been socially constructed by Korean ordinary people. This social construction process creates images for foreigners. Then, these images are so ingrained that most Korean people consider them as the realities of foreigners. Thus, policy-makers may design social and immigrant policies based on these images. This social construction process can also be changed over time and may be different in their residential locations.

The objective of this study is to examine the social construction of foreigners in rural areas in South Korea based on the social construction theory by Anne Schneider and Helen Ingram. For the purpose, this study first historically explores the social construction process of them. Second, the study compares rural areas with urban areas, explaining similarities and differences between them. The transformation of the social construction between generations is also examined here focusing on rural areas. Finally, the study suggests what would be considered in the social construction process of foreign immigrants for local public administration. 


\section{Demographic change in South Korea}

The number of foreign residents has continuously grown. As of 2016, foreign residents in South Korea were 2,049,441 that accounted for $3.96 \%$ of the total South Korean population. Foreign residents include foreign workers, marriage immigrants, foreign students, overseas Koreans, and so on (IT Strategy \& Management Division of Minister of Justice. 2016:38).

The largest numbers of foreign residents were Chinese (including ethnic Koreans called "Chosun-jok") but they came from various countries such as China, Vietnam, the United States, Thailand, and other countries (Table 1).

Table 1. Foreign residents in order of the size of number

\begin{tabular}{|l|r|}
\hline \multicolumn{1}{|c|}{ Year } & \multicolumn{1}{|c|}{2016} \\
\hline Total & $\mathbf{2 , 0 4 9 , 4 4 1}$ \\
\hline China(Chosun-jok) & $1,016,607(627,004)$ \\
\hline Vietnam & 149,384 \\
\hline The United States & 140,222 \\
\hline Thailand & 100,860 \\
\hline Other countries & 642,368 \\
\hline
\end{tabular}

IT Strategy \& Management Division of Minister of Justice. 2016:47.

\section{Foreign workers and international marriages}

Foreign workers and marriage immigrants are the main source of multicultural society in South Korea (Lim, 2009). The largest source of foreign residents was foreign workers while the percentage of foreign workers in total foreign residents had slightly decreased. As of 2016, foreign workers in South Korea were 597,783. Marriage immigrants was another important source of foreign residents that mainly affected the ethnic diversity of South Korea. Recently, over 150,000 immigrants per year migrated to South Korea through international marriage. They were from various countries including China, Vietnam, Japan, the Philippines, and other countries (IT Strategy \& Management Division of Minister of Justice. 2016:44, 52).

These two sources accounted for about $36.6 \%$ of the total foreign residents in South Korea as of 2016. Considering overseas Koreans (18.2\%), short-term visitors (9.3\%), foreign students $(3.7 \%)$ that were not virtually related to foreign immigrants, foreign workers and marriage immigrants could be the main sources of foreign immigrants.

\section{Literature review}

1. Social construction theory

Anne Schneider and Helen Ingram (1993) suggested a theory of policy design based on the concept of social construction. They defined "social constructions are stereotypes about particular groups of people that have been created by politics, culture, socialization, history, the media, literature, religion, and like (p.335)." The theory suggested that the socially constructed perception of a specific target group was connected with policy benefits or 
sanctions toward the group because policy makers would be dependent on how the group was viewed to whole the public. Schneider and Ingram created a matrix using two evaluative dimensions: the vertical axis of the specific group's political power and the horizontal axis of the group's image (called 'social construction'). This matrix consisted of four categories: advantaged, contenders, dependents, and deviants (Table 2). The advantaged groups are characterized as having political power and a good image deserving of respect. Since policy makers are sensitive to political power and the pressure from the public, they may provide the advantaged groups with beneficial policy.

Contenders are considered powerful but less deserving of respect. Policy makers can not directly provide contenders with beneficial policy because the public would not easily approve of it. Therefore, contenders are somewhat covert recipients of beneficial policies. Dependents are considered politically weak in demanding their interests but deserved of sympathy due to their positive images. Deviants are politically weak and have negative images. So, they usually excluded from the public. The possibility of being recipients of beneficial policies are very small. According to Ingram and Schneider, understanding social constructions of specific groups can help to explain "who get what, when, and how (p.346)". In addition, this social construction process can be changed over time. Policy makers are influenced by socially constructed perceptions but they also lead and manipulate the social construction process to get policy effects as intended.

Table 2. Social constructions and political power: four categories of target groups

\begin{tabular}{|c|c|c|c|}
\hline \multirow{2}{*}{\multicolumn{2}{|c|}{ Categories }} & \multicolumn{2}{|c|}{ Social Constructions } \\
\hline & & Positive & Negative \\
\hline \multirow{2}{*}{$\begin{array}{l}\text { Political } \\
\text { Power }\end{array}$} & Strong & $\begin{array}{l}\text { Advantaged: } \\
\text { Benefits are oversubscribed. } \\
\text { Burdens are undersubscribed. }\end{array}$ & $\begin{array}{c}\text { Contenders: } \\
\text { Benefits are sub-rosa. } \\
\text { Burdens are symbolic and overt. }\end{array}$ \\
\hline & Weak & $\begin{array}{l}\text { Dependents: } \\
\text { Benefits are undersubscribed } \\
\text { Burdens are oversubscribed } \\
\text { but deserved of sympathy. }\end{array}$ & $\begin{array}{l}\text { Deviants: } \\
\text { Benefits are very undersubscribed. } \\
\text { Burdens are very oversubscribed } \\
\text { and excluded from the public. }\end{array}$ \\
\hline
\end{tabular}

Combining and re-editing two tables from Anne Schneider and Helen Ingram. 1993:336-337.

2. The historical social construction of multicultural immigrants in South Korea

According to a study by Seung Jun Han \& Chisung Park(2011), marriage immigrants and foreign workers begun deviant groups in the early 2000s. Exploring foreign policies and news articles related international marriage and foreign workforce, the study concluded that the social construction process of the two groups became different as time passed by. As of 2009, Marriage immigrants were considered a dependent group while foreign workers still remained as a deviant group (p.75) (Table 3). Similarly, Chisung Park, Seung-Jung Han, \& Pan Suk Kim(2013) concluded that female work immigrants remained deviants. In the study, the social construction of female marriage immigrants was located between dependents and 
deviants while authors suggested an optimistic view on female marriage immigrants in the future.

Table 3. The historical change of social construction of marriage immigrants and foreign workers:

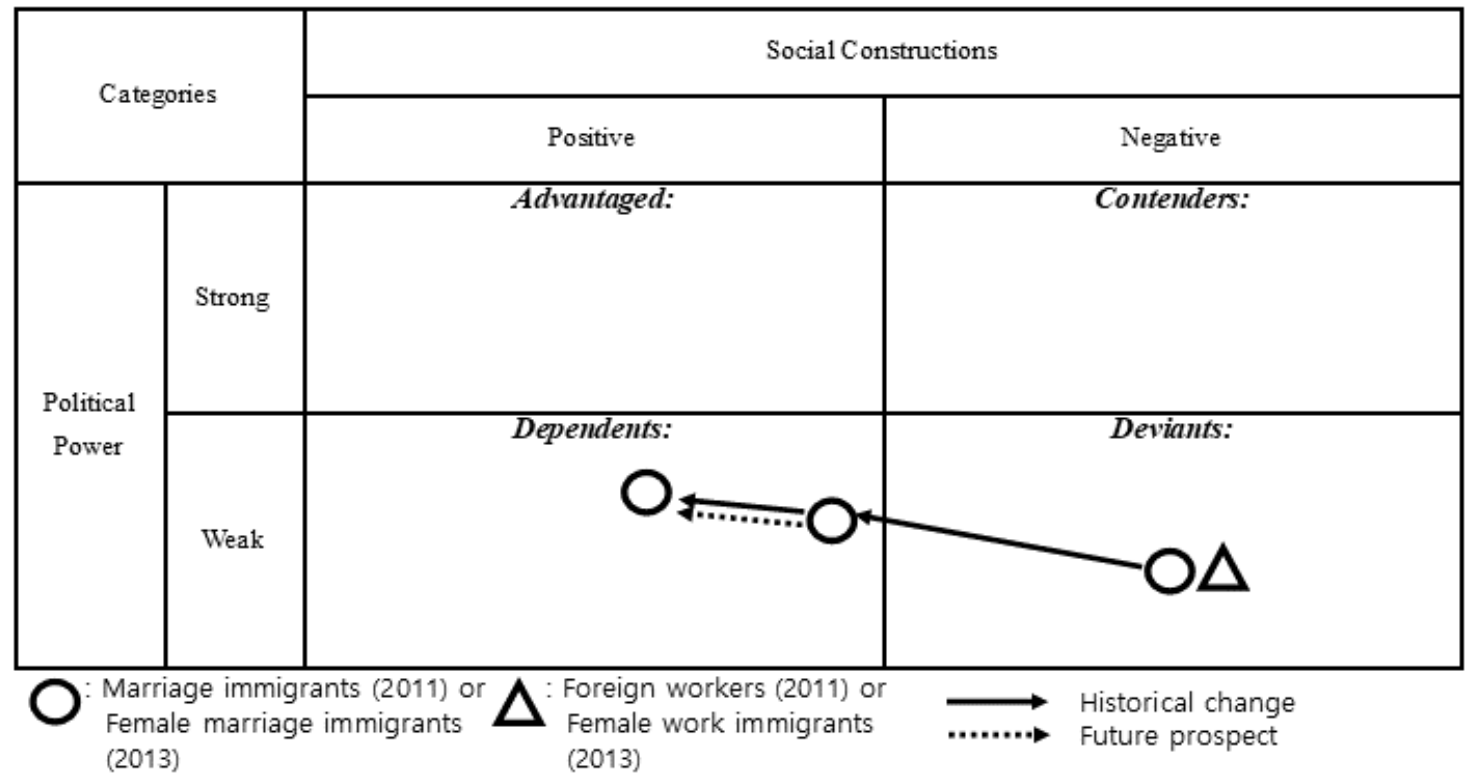

Combination of the tables from Seung Jun Han \& Chisung Park. 2011: 77. \& Chisung Park, Seung-Jung Han, \& Pan Suk Kim. 2013:134.

However, there was a gap between document analysis and survey data in terms of the social construction of female marriage immigrants. The result of social construction based on survey data said something different about South Korean's perception about foreigners. In the Korean general social surveys(KGSS) conducted by Survey Research Center in 2008 and 2010, Korean people expressed slightly negative attitude to the increase of female marriage immigrants while the image of them was gradually improved (Table 4). In the same surveys, the image of foreign workers was not bad as the two articles mentioned above concluded. Rather, the social construction of foreign workers was slightly improved. 
Table 4. The Social construction of marriage immigrants and foreign workers based on KGSS:

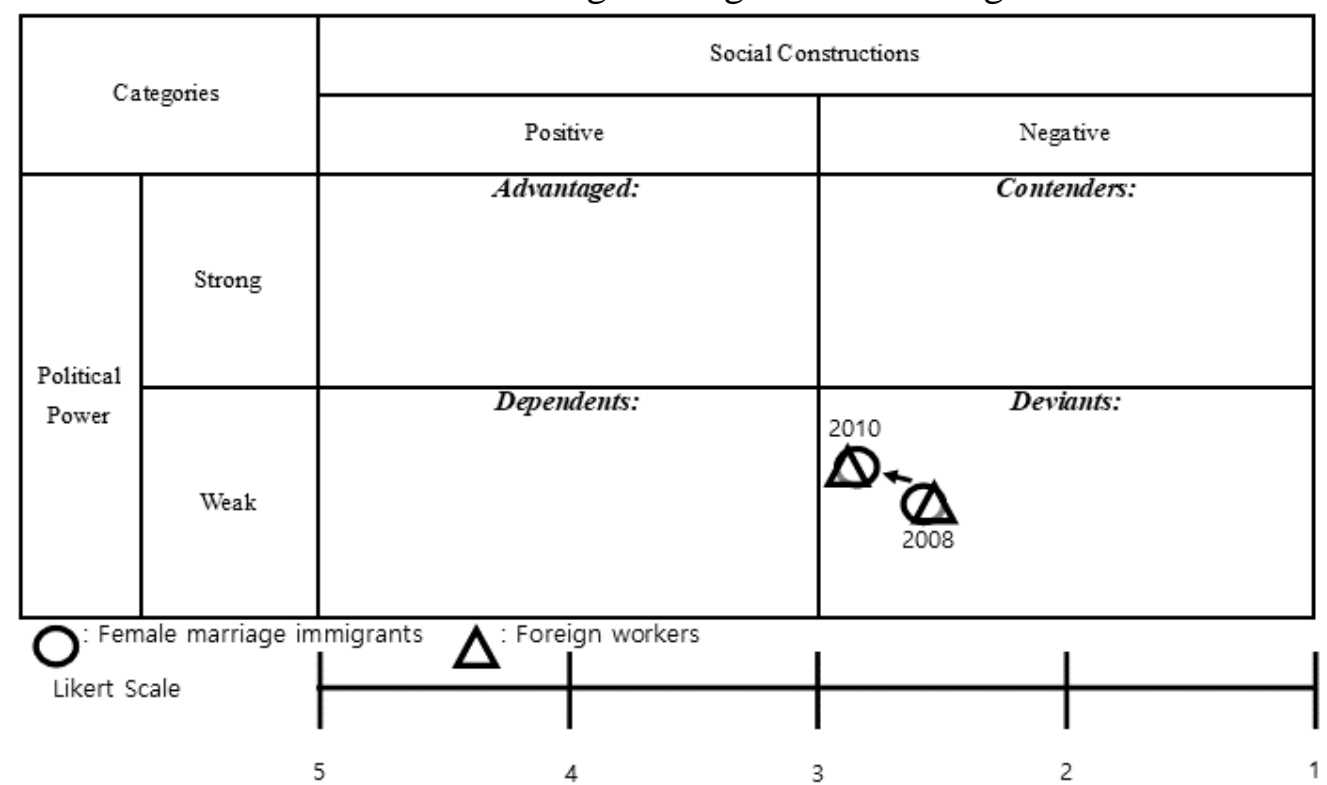

1) Survey questions: The number of female marriage immigrants and foreign workers

2) $1=$ reduced a lot, $2=$ reduced a little, $3=$ remain the same as it is, $4=$ should be increased a little, $5=$ should be increased a lot

3) Data: Female marriage immigrants (2.77 in 2010, 2.58 in 2008), Foreign workers (2.84 in 2010, 2.52 in 2008).

Considering policy makers reflect on the stereotype of foreign immigrants in making foreign policies, the difference between documents and survey data should be reviewed and interpreted to legislate and implement purposeful foreign policies for both ordinary Koreans and foreign immigrants.

\section{Data source}

This study aims to select data from 'the 2015 study on multicultural acceptability in Korea' as a national survey data, investigate the current status about multicultural acceptability in both urban and rural areas, and find differences by generations as well as areas focusing on rural region. Targets of the national survey were the adults and the youth in both regions. Various questions were utilized to grasp the multicultural acceptability of Korean people. Among these questions, this study selects and analyzes twenty-six questions commonly used for the adult and the youth respondents. The sample size for the adults was 4,000 respondents from 19 and 74 years old. Among total respondents, 2,006 were male and 1,994 were female. 3,484 were from urban areas and 516 were from rural areas. These rates were based on the data from the 2010 Korean population and housing consensus. The survey for adult respondents was conducted from 2015.09.10 2015.11.10. The margin of sampling error was plus or minus 1.55 percentage points at a 95 percent confidence level.

The sample size for the youth was 3,640 respondents from 12 to 18 years old. Among 
total respondents, 1,624 were male and 2,016 were female. 2,695 were from urban areas and 1,141 were from rural areas. These rates were based on the data from the 2014 Korean statistical yearbook of education. The survey for youth respondents was conducted from 2015.09.10 2015.10.31. The margin of sampling error was plus or minus 1.62 percentage points at a 95 percent confidence level.

\section{Main findings about Korean attitude to multicultural phenomenon by areas and generations}

1. The attitude to the homogeneous society

Although Korean adults, particularly rural residents, still had a good feeling for remaining a homogeneous society, they expressed an almost neutral attitude about the impact of multicultural immigrants on social cohesion in South Korea (Table 5).

In the case of Teenagers, they did not have a pride for remaining a homogeneous society. Rather, they showed a somewhat negative stance on the view of remaining a homogenous society for competitiveness. They also slightly disagreed with the statement of "social cohesion is generally undermined by multicultural immigrants." But teenagers in rural areas expressed relatively more concerns about the negative impact of multicultural immigrants on social cohesion than urban teenagers.

Table 5. The attitude to the ethnically homogeneous society by areas and generations

\begin{tabular}{|l|c|c|c|c|c|c|}
\hline \multirow{2}{*}{ Categories of the attitude } & \multicolumn{3}{|c|}{ Adults } & \multicolumn{3}{c|}{ Teenagers } \\
\cline { 2 - 8 } & Rural & Urban & t-test & Rural & Urban & t-test \\
\hline $\begin{array}{l}\text { (1) We must be very proud of ourselves } \\
\text { for historically remaining a } \\
\text { homogeneous society }\end{array}$ & 3.61 & 3.51 & $*$ & 3.08 & 3.09 & \\
\hline $\begin{array}{l}\text { (2) To remain a homogeneous society is } \\
\text { good for South Korea to stay competitive }\end{array}$ & 3.33 & 3.28 & & 2.85 & 2.87 & \\
\hline $\begin{array}{l}\text { (3) Social cohesion(or solidarity) is } \\
\text { generally undermined by multicultural } \\
\text { immigrants }\end{array}$ & 3.08 & 3.12 & & 2.64 & 2.57 & $*$ \\
\hline Cronbach's $\alpha$ for the three questions & \multicolumn{3}{|c|}{0.674} & & 0.743 & \\
\hline
\end{tabular}

1) Likert Scale: $1=$ strongly disagree, $2=$ disagree, $3=$ neither agree nor disagree, $4=$ agree, 5=strongly agree; 2$) * P<.05$

2. The attitude to immigrants and foreign workers

While adult respondents had their neutral attitude for the number of immigrants and the impact of foreign workers on Korean job market and economy, they were concerned about crime rates caused by foreign workers. In three of four categories, rural residents were more generous toward immigrants and foreign workers than urban residents. These differences were statistically meaningful.

On the contrary, rural teenagers were relatively less generous than urban teenagers 
although they are more tolerant toward immigrants and foreign workers than adults. These urban/rural differences were statistically significant in two of four categories (Table 6).

Table 6. The attitude to immigrants and foreign workers by areas and generations

\begin{tabular}{|c|c|c|c|c|c|c|}
\hline \multirow{2}{*}{ Categories of the attitude } & \multicolumn{3}{|c|}{ Adults } & \multicolumn{3}{|c|}{ Teenagers } \\
\hline & Rural & Urban & t-test & Rural & Urban & t-test \\
\hline $\begin{array}{l}\text { (1) The number of immigrants to South } \\
\text { Korea nowadays }\end{array}$ & 2.95 & 2.87 & $*$ & 3.32 & 3.35 & \\
\hline $\begin{array}{l}\text { (2) Foreign workers take jobs away } \\
\text { from Korean people }\end{array}$ & 2.84 & 3.00 & $*$ & 2.83 & 2.80 & \\
\hline $\begin{array}{l}\text { (3) Foreign workers are generally not } \\
\text { good for the South Korean economy }\end{array}$ & 3.02 & 3.06 & & 2.63 & 2.53 & $*$ \\
\hline $\begin{array}{l}\text { (4) Foreign workers increase crime } \\
\text { rates }\end{array}$ & 3.23 & 3.37 & $*$ & 2.73 & 2.56 & $*$ \\
\hline $\begin{array}{l}\text { Cronbach's } \alpha \text { for three questions about } \\
\text { foreign workers }\end{array}$ & \multicolumn{3}{|c|}{0.730} & \multicolumn{3}{|c|}{0.766} \\
\hline
\end{tabular}

1) Likert Scale for immigrants: $1=$ reduced a lot, $2=$ reduced a little, $3=$ remain the same as it is, $4=$ should be increased a little, $5=$ should be increased a lot

2) Likert Scale for foreign workers: $1=$ strongly disagree, $2=$ disagree, $3=$ neither agree nor disagree, 4=agree, 5=strongly agree; 3) $* P<.05$

\section{The Attitude to ethnic \& civic elements for being truly South Korean}

People in favor of ethnic elements tend to focus on ancestry, bloodlines, cultural assimilation, and place where people was born and brought up. They are "likely to be associated with weaker support for multiculturalism and higher levels of concern about immigration". In contrast, people in favor of civic elements tend to emphasize speaking national language, respecting political institutions, having possessing national citizenship, contributing developments of the nation and so on. They are likely to be generous for immigrants and "to be more willing to extend a degree of fellow-feeling to immigrants" (Heath and Tilley. 2005:120).

Even though Korean adults admitted the importance of ethnic elements, they emphasized civic elements rather than ethnic elements for being truly South Korean (Table 7). Except each one category in both the ethnic and the civic elements, there were no significant difference between rural and urban respondents.

However, teenagers did not focus much on ethnic elements to be truly South Korean. Although they relatively focused on civic elements but the teenagers' Likert Scale scores on civic elements were lower than the adults' scores. Unlike the adult case, the Likert Scale scores of rural areas in four of six categories on ethnic elements were significantly higher than the scores of urban areas, meaning that rural teenagers might be more conservative than urban teenagers. 
Table 7. The Attitudes to ethnic and civic elements for being truly South Korean by areas and generations

\begin{tabular}{|c|c|c|c|c|c|c|}
\hline \multirow{2}{*}{$\begin{array}{l}\text { 1. Categories of the attitude } \\
\text { :ethnic elements }\end{array}$} & \multicolumn{3}{|c|}{ Adults } & \multicolumn{3}{|c|}{ Teenagers } \\
\hline & Rural & Urban & t-test & Rural & Urban & t-test \\
\hline (1) To have been born in South Korea & 2.94 & 2.94 & & 2.43 & 2.35 & $*$ \\
\hline (2) To have South Korean ancestry & 2.98 & 3.01 & & 2.26 & 2.14 & $*$ \\
\hline (3) To have South Korean father & 3.04 & 3.10 & & 2.48 & 2.35 & $*$ \\
\hline (4) To have South Korean mother & 3.00 & 3.07 & & 2.47 & 2.34 & $*$ \\
\hline $\begin{array}{l}\text { (5) To have lived in South Korea for } \\
\text { most of one's life }\end{array}$ & 2.80 & 2.90 & $*$ & 2.58 & 2.56 & \\
\hline $\begin{array}{l}\text { (6) To keep alive the traditional ways } \\
\text { of South Korea }\end{array}$ & 3.08 & 3.09 & & 2.67 & 2.62 & \\
\hline Cronbach's $\alpha$ for questions above & \multicolumn{3}{|c|}{0.879} & \multicolumn{3}{|c|}{0.874} \\
\hline \multirow{2}{*}{$\begin{array}{l}\text { 2. Categories of the attitude } \\
\text { :civic elements }\end{array}$} & \multicolumn{3}{|c|}{ Adults } & \multicolumn{3}{|c|}{ Teenagers } \\
\hline & Rural & Urban & t-test & Rural & Urban & t-test \\
\hline (1) To be able to speak South Korean & 3.28 & 3.26 & & 3.00 & 3.00 & \\
\hline $\begin{array}{l}\text { (2) To respect South Korean Political } \\
\text { Institutions and Laws }\end{array}$ & 3.32 & 3.26 & & 2.94 & 2.97 & \\
\hline (3) To feel South Korean & 3.30 & 3.29 & & 3.16 & 3.18 & \\
\hline (4) To have South Korean citizenship & 3.26 & 3.28 & & 2.94 & 2.93 & \\
\hline $\begin{array}{l}\text { (5) To have contribution to the } \\
\text { development of South Korea }\end{array}$ & 3.16 & 3.07 & $*$ & 2.73 & 2.69 & \\
\hline Cronbach's $\alpha$ for questions above & \multicolumn{3}{|c|}{0.810} & \multicolumn{3}{|c|}{0.797} \\
\hline
\end{tabular}

1) Likert Scale: $1=$ Strongly disagree, $2=$ somewhat disagree, $3=$ mostly agree, $4=$ strongly agree 2) $* P<.05$

\section{Experience and Need}

Rural adults had more experienced multicultural events/activities such as festivals and sports day $(8.5 \%)$ than urban adults $(4.4 \%)$ for their lifetime (Table 8$)$. In the category of volunteer activities and club activities, no significant difference was observed between two areas. Only about one-twenties of adult respondents took multicultural education. They recognized and agreed the need of multicultural education and activities.

In the case of teenagers, the rate of experiencing multicultural education was five times higher than the rate of activities with multicultural students for the period of 2014.09.01. 2015.08.31. Unlike adults, teenagers did not recognize the need of multicultural activities and this trend was relatively strong in rural areas. 
Table 8. Experience and Need of multicultural education and events/activities

(Unit: \% for experience and scores for need)

\begin{tabular}{|c|c|c|c|c|c|c|}
\hline \multirow{2}{*}{ Categories } & \multicolumn{3}{|c|}{ Adults } & \multicolumn{3}{|c|}{ Teenagers } \\
\hline & Rural & Urban & t-test & Rural & Urban & t-test \\
\hline (1) Experience and & $4.5 \%$ & $5.5 \%$ & & $24.4 \%$ & $27.5 \%$ & \\
\hline Need for multicultural education ${ }^{a}$ & 3.62 & 3.54 & $*$ & N/A & N/A & \\
\hline $\begin{array}{l}\text { (2) Experience } \text { of multicultural }^{\mathrm{a}} \text { of } \\
\text { events/activities like festivals and } \\
\text { sports day: for adults } \\
\text { Experience }^{\mathrm{a}} \text { for events/activities with } \\
\text { multicultural students: for } \\
\text { teenagers }\end{array}$ & $8.5 \%$ & $4.4 \%$ & & $4.2 \%$ & $5.1 \%$ & \\
\hline $\begin{array}{l}\text { Need for multicultural events/ } \\
\text { activities }\end{array}$ & 3.48 & 3.40 & & 2.62 & 2.73 & $*$ \\
\hline $\begin{array}{l}\text { (3) Experience of volunteer activities for } \\
\text { helping foreigners }\end{array}$ & $4.3 \%$ & $4.8 \%$ & & N/A & N/A & \\
\hline Need for volunteer activities & 3.59 & 3.45 & * & N/A & N/A & \\
\hline (4) Experience and & $3.3 \%$ & $2.4 \%$ & & N/A & N/A & \\
\hline $\begin{array}{l}\text { Need for club activities with } \\
\text { foreigners and immigrants }\end{array}$ & 3.36 & 3.31 & & N/A & N/A & \\
\hline
\end{tabular}

1) Likert Scale for types of needs: $1=$ nothing at all, $2=$ slightly weak, $3=$ neutral, $4=$ slightly strong, 5=very strong; 2) $* P<.05$; 3) ${ }^{\text {a }}$ For adults: Life-time experience; for teenagers: experience for the period of 2014.09.01. 2015.08.31.

\section{Implications and conclusion}

1. The difference by areas and generation

In South Korea, rural and urban areas have been generally recognized as different entities. Rural areas have been believed to be more conservative, traditional, and mono-ethnic than urban areas. However, the influence of increasing multicultural immigrants changed the characteristics of rural areas. Rural residents had more foreign neighbors and had more experienced events or activities with foreigners and immigrants.

As a result, adults in rural areas showed the double-sidedness. On the one hand, they were still proud of their historical homogeneous society and felt the strong sense of their local areas. On the other hand, they were favorable to foreign immigrants and emphasized civil elements rather than ethnic elements as conditions to be truly Korean. The difference between rural and urban area was not big but existed in some categories with statistical significance saying that adults in rural areas were slightly more generous than adults in urban area.

Meanwhile, teenagers in rural area showed more favorable attitude to multicultural immigrants in comparison with rural adults. However, among teenagers, the rural youth were tended to be relatively conservative. They were less favorable to foreign immigrants and 
emphasized ethnic elements as compared to the urban youth. This tendency was opposite to the result of adult's case. In addition, there were no significant difference between rural and urban teenagers in terms of the sense of belonging and the preference for Korean mono-ethnic tradition.

\section{Transformation of social construction by generation}

The 2015 national survey data showed that the social construction of foreign immigrants by the Korean adults was not much changed as compared to the previous studies mentioned-above. However, teenagers who had little political power were more generous than adults (Table 9). This phenomenon is hopeful in the aspect of the development of social construction of foreign immigrants but it was necessary to evaluate whether the development was due to foreign policies or the characteristics of the current youth.

Table 9. The difference of social construction by generation

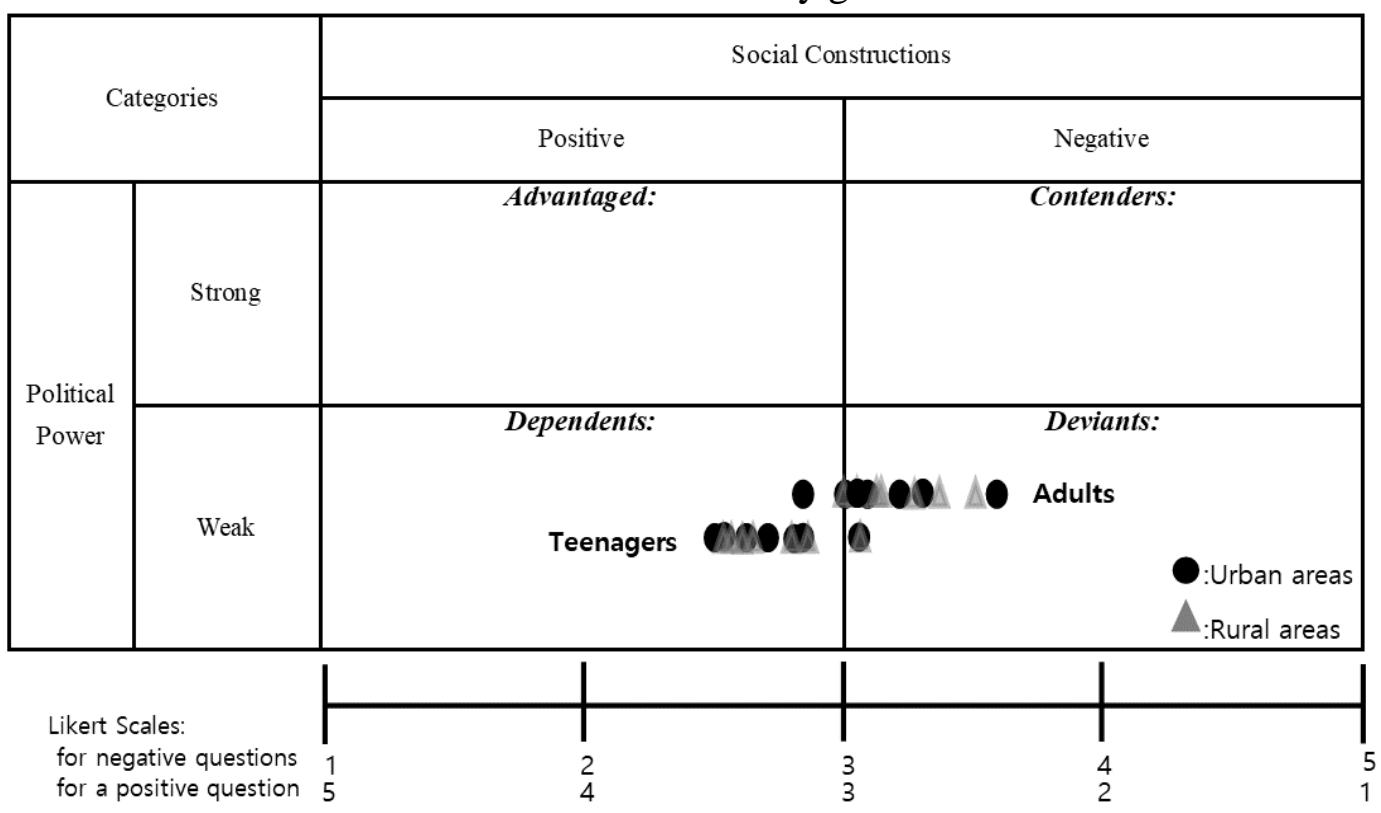

3. Local policy implications about foreign immigrants

1) Adults in rural areas

Even if residents in rural communities were slightly favorable rather than urban residents in some categories, they had still negative attitude overall to foreign immigrants. Therefore, as rural areas have consistently changed in the aspect of the racial and ethnic diversity, it is important to understand the reality of foreign neighbors. But they rarely had experienced multicultural education while they recognized needs for multicultural education, events, and activities.

In this context, local policy-makers should provide rural residents with various opportunities for education and activities with immigrants. The policy priority would be multicultural education (3.62) and volunteer activities for helping foreigners and immigrants 
(3.59) as shown in Table 8. Multicultural education may move the social construction of foreign immigrants in rural areas from a 'negative' to a 'favorable' attitude. Volunteer activities may increase mutual understanding and help foreign immigrants to be qualified for civil elements that rural adult respondents had an emphasis on to be Korean. In addition, local foreign policies for education and volunteer activities would make all people in rural region stay together regardless of nationality without undermining social solidarity by multicultural immigrants.

2) Teenagers in rural areas

Although the rural teenagers were tended to be more generous for immigrants and foreign workers than adults, they had a slightly strict attitude to foreigners rather than the rural youth. Therefore, like adults, teenagers in rural areas also need the multicultural education. In fact, they had the fewer experience of multicultural education than teenagers in urban areas (Table 8).

A severe problem was that the rural youth rarely had the experience for events/activities with multicultural students and did not felt the need for events/activities (Table 8). If local policy makers ignore these facts, they may have an apathy to multicultural classmates. Moreover, the atmosphere of unconcern may cause some inhospitality for foreign students being interlocked with the relatively strict attitude to foreigners. Therefore, it is urgent and necessary to develop various programs that can attract both Korean teenagers and multicultural students.

\section{References}

Han, Seung Jun \& Park, Chisung. (2011). The impact of public policy on social construction of foreigners: Comparative case study of foreign workers and marriage immigrants. Korean Policy Studies Review. 20(1), 51-81

Hansen, Holley E. \& Hesli, Vicki L.. (2009). National identity: Civic, ethnic, hybrid, and atomised individuals. Europe-Asia Studies. 61(1), 1-28.

Heath, Anthony F. and Tilley, James R. (2005). British national identity and attitudes towards immigration. International Journal on Multicultural Societies. 7(2), 119-132.

Jang, Joon-oh. (2015). Korean perceptions on foreign immigrants. IOM MRTC working paper (2015-07), 1-22.

IT Strategy \& Management Division of Minister of Justice. (2016). Korea Immigration Service Statistics 2016. Minister of Justice.

Lim, Hyung-Baek. (2009). A study on the differences of multicultural society between urban and rural areas in Korea and its policy differentiation. Journal of the Korean Regional Development Association. 21(1), 51-74.

Lim, Timothy. (2009). Who is Korean? Migration, immigration, and the challenge of multiculturalism in homogeneous societies. The Asia-Pacific Journal. 7(30), 1-22.

Park, Chisung., Han, Seung-Jung \& Kim, Pan Suk. (2013). The formation of social 
constructions of female marriage migrants and female work migrants in South Korea. Asian Women. 29(4), 107-140.

Schneider, Anne and Ingram, Helen (1993). Social construction of target populations: Implications for politics and policy. The American Political Science Review. 87(2), 334-347.

Survey Research Center. Korean General Social Surveys (KGSS) in 2008 and 2010. Seoul: Sungkyunkwan University. Retrieved from http://kgss.skku.edu/

The Korean Women's Development Institute (2015). The 2015 Study on Multicultural Acceptability in Korea. Ministry of Gender Equality \& Family.

Yoon, In-jin et al. (2010). South Koreans' Perceptions on Foreign Workers and Multicultural Society (ISBN:978-89-268-20982-2 93330). Kyunggi-do: Korean Studies Information Co., Ltd. South Korea.

Yoon, In-jin \& Song, Young-ho. (2011). South Koreans' perceptions of national identity and acceptance of multiculturalism. The Korean Journal of Unification Affairs. 23(1), 143 192. 